\title{
The Influence of Online Reputation and Product Heterogeneity on Service Firm Financial
}

\section{Performance}

\begin{abstract}
Using two proprietary datasets, ReviewPro's Global Review Index and Smith Travel Research's Performance database, we examine the influence of online review scores on service firm financial performance. We conceptualize online reviews as a measure of a service firm's reputation and demonstrate that higher scores have a positive relationship to a hotel's financial performance as measured by Revenue per Available Room (RevPAR). We demonstrate that a 1-percent increase of a hotel's online reputation score is related to a 0.99-percent increase in RevPAR. We also demonstrate that naturally occurring differences in the heterogeneity of different product classes moderates the relationship between review score and performance. The influence of online reviews monotonically decreases as hotel class level increases (e.g. upscale hotels are less affected by reviews scores than midscale hotels). We also demonstrate that when controlling for occupancy, online consumer review ratings, have a greater influence on a firms pricing power (ADR) for service/product categories with more depth, i.e. for products positioned within categories of diverse offerings. As a robustness check we examine the influence of scores at the individual rather than aggregate level by using choice data from a major North American travel agent. Replicating our aggregate results, choice data affirms the positive impact of review scores on hotel selection as well as the moderating role of hotel type.
\end{abstract}




\section{The Influence of Online Reputation and Product Heterogeneity on Service Firm Financial}

\section{Performance}

Online consumer reviews have become a dominant force in the marketing of both products and services. Firms are increasingly looking to online review aggregators such as Yelp and Tripadvisor to help advertise their products and shoppers are consistently referencing user-generated product reviews before purchasing (Archak, Ghose, and Ipeirotis 2011). Due to their suggested influence on a firm's reputation the strategic management of these online reviews has become an increasingly important focus of the firm (Dellarocas 2006). Companies actively manage reviews by responding to review complaints and complements and use their online review ranking to market their services. The aggregation and presentation of these consumer reviews has, in itself, become a viable business model. Angie's List charges membership to view and post online reviews of local service companies and contractors. TripAdvisor assists customers by posting reviews and opinions of travel-related content, providing over 75 million reviews generated by some 32 million users (tripadvisor.com).

Firms use a number of mechanisms, including traditional advertising, to build brand reputation and reduce the perceived risk of a service purchase (Ross 1975). Heterogeneity related to service experiences is particularly important given that high variability in service quality can lead to dramatically different consumer experiences even from the same producer or branded outlet. These characteristics increase the potential risks to both consumers, looking to purchase a service based product, and sellers, looking to maximize the utilization of service products that cannot be stored and sold at a future date. This heterogeneity can amplify the perceived risk of service based purchases 
increasing the importance of a firm or brand's reputation for delivering quality service. However, a firm's reputation is also the result of multiple sources of information outside the direct control of the firm. Empowered consumers now have access to multiple channels of information including consumer created content that assists them in their purchase decisions. New media has enabled consumers to share such content with an entire community of users quickly and efficiently challenging established methods of relationship management. While offline WOM is limited by geographic and social boundaries (Ellison and Fudenberg 1995), online WOM has both global presence and enduring content resulting in an increasingly significant role in the purchase decisions of consumers.

We know that online user-generated reviews can impact the sales of products such as books (Chevalier and Mayzlin 2006), influence movie box office sales (Liu 2006) and impact the reputation of sellers of products and services (Resnick et al. 2006). Factors such as the valence of review (Forman, Ghose, and Wiesenfeld 2008) and review volume (Liu 2006) have been found to significantly impact sales. Researchers have found that an extra half-star rating on the peer review site Yelp results in a 19 percent greater likelihood that a restaurant's seats will be full during peak dining times (Anderson and Magruder 2012). This effect is further strengthened when other information about the restaurant is scarce.

Though some work in the context of services has begun to examine the impact of reviews in the hospitality sector (Vermeulen and Seegers 2009; Ye, Law, and Gu 2009), these studies have either used experiments to simulate the purchase experience or had insufficient data to link consumer reviews with actual financial performance. Unlike previous work, this paper combines two unique databases to evaluate the role consumer reviews have on the actual financial performance of firms 
that sell service products and thus answers the call from both the marketing (Godes and Mayzlin 2004) and services literature (Libai et al. 2010) to investigate the market outcomes of WOM activity on various measures of a firm's performance.

The intangibility of products in the service setting provides a unique set of issues to examine the influence of WOM. For example, many models that investigate the impact of WOM often fail to account for the limited availability or perishability of services such as hotel rooms or restaurant seats (see Elberse and Eliashberg 2003 for exception). Occupancy rates at hotels are constrained, and therefore managers must make decisions regarding pricing and demand to maximize overall revenue. Unlike movie tickets and books that have, for the most part, set prices, prices for hotel rooms can vary significantly as the firm works to maximize total revenue. Our measure of financial performance, revenue per available room (RevPAR), the industry standard for measuring financial performance, takes into consideration both occupancy rate and price. We can therefore examine two important levers of financial performance related to quality perceptions, volume of purchases and price premiums (Zeithaml 2000).

This paper examines the impact of online consumer reviews on firm performance by using ReviewPro's Global Review Index as a firm level measure of WOM and Smith Travel Research's hotel performance data. We then provide a robustness check for our findings by examining the impact of online review scores on consumers' purchase decision at point of purchase by tracking consumers' behavior utilizing consumer panel data from a major North American Online Travel Agent (OTA).

In addition to exploring the main effect of online consumer reviews on performance, we explore the moderating influence of heterogeneity of product offering on this relationship. We find that 
online consumer reviews have greater impact on product classes with greater heterogeneity. Previous research has demonstrated that various product and consumer characteristics may moderate the relationship between online reviews and firm performance (Anderson and Magruder 2012). Our design controls for the type of product (hotel room) while examining the moderating role of naturally occurring variance in product quality in different classes of hotel properties. We also examine the impact of online WOM on pricing power (ADR) while controlling for occupancy. This allows us to examine the ability of different classes of hotel properties to use to different levers or RevPAR, price and occupancy, to maximize financial performance.

\section{FIRM REPUTATION AND ITS SOURCES}

In services marketing, reputation plays a particularly salient role given that pre-purchase evaluation of a service is often difficult due to the intangibility of the product offering (Weigelt and Camerer 1988). Though the concept of reputation is often analyzed at the corporate level we examine the online reputation of individual service outlets that may or may not be part of a branded chain. This examination at the unit level is in line with studies of online sellers examining the impact of reputation on buyer behavior (Resnick and Zeckhauser 2002; Lucking-Reiley et al. 2007).

We use Herbig and Milewicz's $(1993,18)$ definition of reputation that states "Reputation is an aggregate composite of all previous transactions over the life of the entity, a historical notion, and requires consistency of an entity's actions over a prolonged time.” Reputation not only includes a customer's direct experiences but any other form of communication that provides information about the seller (Gotsi and Wilson 2001). Reputation is thus an aggregate composite of a customer's internal first hand experiences and external sources of information resulting in a longitudinal 
assessment of not only service quality but consistency of that quality. Internal sources of information include prior contact with the product or service directly experienced by the consumer and stored in memory (Murray 1991). External sources include those controlled and communicated by the firm itself and third party sources that are independent of the firm. In this paper we focus on an external source that is not controlled by the firm, online WOM in the form of aggregate consumer review scores. These aggregate consumer review scores represent a measure of online seller reputation.

Direct experiences with a service provider help to establish and update a firm's reputation in the mind of the consumer. Though direct experience and observation may provide the most accurate, credible and relevant product assessment (Wright and Lutz 1993) this type of information gathering is costly and often impractical in the service setting. Though sellers of tangible products may offer free trials and refunds to reduce consumer risk; due to the unique nature of services, which often includes perishability and inseparability, this is often not possible. Unlike tangible goods, many service products including hotel stays are geographically bound, therefore increasing the costs associated with pre-trial or observation. Consumers therefore have limited breadth of direct experience, forcing them to rely on alternative sources to evaluate firm reputation. Even when consumers do experience the product first hand, over time services can be highly variable even from the same producer. Past experiences, therefore, may fail to reflect a firm's true service reputation (Eberl and Schwaiger 2005). In addition to the various service interactions that create heterogeneous consumer experiences the organizational form of many service based firms creates further variance. As mentioned earlier, reputation implies longitudinal assessment. Given that many service products are purchased infrequently from the same producer, direct consumer 
experiences may not have the depth of experience to form an overall assessment of a firm's reputation over time. Without repeated purchases and input from other monitors, individuals suffer from significant informational asymmetry, reducing their ability to assess the reputation of the seller.

Another source of reputation is third party product reviews from experts. These may include established rating agencies like Consumer Reports or Zagat that evaluate and score products on various performance measures. Third party product reviews are often viewed as more credible than information produced directly by the company (Zhu and Zhang 2010). However, expert reviews may not be as predictive of sales (Reinstein and Snyder 2005) as experts' opinions of experiential products may fail to reflect the average consumer's tastes or preferences (Eliashberg and Shugan 1997). This heterogeneity among evaluators may result in uncertainty among buyers, resulting in further information search (Shapiro 1982). Reviewers of experiential goods may also receive service experiences that are better than the average consumer. For example, the NY Times critic or Zagat rater are often singled out and provided superior service beyond that received by the average consumer (Blank 2007). Therefore expert reviews of an experience may be less diagnostic and thus less relevant for the average consumer.

After prior experience, WOM has been shown to be the most important external source of information to reduce purchase risk (Lutz and Reilly 1974). Though having greater breadth and depth than direct personal experience, traditional WOM is still limited by geographic and social boundaries (Ellison and Fudenberg 1995). Online WOM, on the other hand, has both global presence and enduring content resulting in an increasingly significant role in the purchase decisions of consumers. One reason that online consumer reviews are so influential is the perception that they reduce risk and provide more credible and trustworthy information (Bickart and Schindler 2001). 
Researchers have argued that online feedback mechanisms have a larger impact on the firm than traditional WOM due to the unprecedented scale and ability to measure and control customers' reviews and provide personalized feedback (Dellarocas 2003). Online WOM provides significant depth given that aggregate scores are updated on a continuous basis. Consistent with Bayesian hypotheses, research has demonstrated that the number of reviews used in the aggregate score impacts the influence of review scores on performance (Zhu and Zhang 2010).

\section{THEORY AND HYPOTHESES}

\section{WOM and Firm Performance}

We view online reviews as an important component of a firm's online reputation. Higher firm reputation has been associated with greater firm performance (Rindova et al. 2005) and numerous studies have linked both online consumer reviews (Senecal and Nantel 2004) and professional critic ratings (Reinstein and Snyder 2005) to increased consumer demand. Sellers with high consumer ratings are also more likely to sell their products in the context of auctions (Resnick and Zeckhauser 2002) and attract more bidders and higher prices for their items (Lucking-Reiley et al. 2007).

Consumer reviews have also been shown to impact aggregate sales (Berger, Sorensen, and Rasmussen 2010) and pricing power (Tirunillai and Tellis 2012). Work examining online WOM activity and aggregate firm performance has demonstrated that negative WOM leads to lower stock price (Luo 2009), that online referrals lead to higher customer acquisition when compared to traditional advertising (Trusov, Bucklin, and Pauwels 2009) and that WOM customers add nearly twice as much long term value to the firm (Villanueva, Yoo, and Hanssens 2008).

However, work examining the influence of WOM on a firm's performance has focused almost 
exclusively on either overall sales or pricing power. Examining a service product like a hotel room stay, which has both a variable pricing structure and limited availability, provides the opportunity to examine the impact of WOM on overall firm financial performance as measured by revenue per available room (RevPAR). Based on prior literature we therefore propose the following:

H1: Higher online consumer review ratings are positively related to a firm's financial performance (RevPAR).

\section{Heterogeneity}

One defining factor for service products is heterogeneity or variability in the service offering. Unlike tangible products that can be mass produced, most service products are the product of co-creation, often incorporating multiple actors and complex interactions. Even in a single outlet, service experiences can vary dramatically depending on the employee, customer and time of day (Zeithaml and Bitner 2003). Variance leads to greater uncertainty and consumer risk for service experiences (Murray and Schlacter 1990), increasing the importance of firm reputation in attracting customers.

When the perceived risk and uncertainty associated with the product or service is high consumers are more likely to engage in information search and rely on other people's comments (Murray 1991). For example, when information about a restaurant is scarce, online review scores are found to have a greater impact on consumer demand (Anderson and Magruder 2012). Consumers are also less price sensitive when purchasing a brand with high credibility due to the reduction in risk and uncertainly (Erdem, Swait, and Louviere 2002). When consumers view a product or class of products as containing significant variance, then a firm's reputation, as measured 
by online consumer review ratings, should have a greater effect on purchase and subsequent firm financial performance. We therefore propose the following:

H2: The impact of online consumer review ratings on a firm's financial performance

(RevPAR) will be moderated by product heterogeneity. Online consumer review ratings will have a greater impact on product classes with greater heterogeneity.

\section{Pricing Power}

We have argued above that greater heterogeneity related to service offerings drives the impact of online WOM on firm financial performance in the form of RevPAR. The improvement in online reputation represented by strong online WOM reduces the level of service quality uncertainty in the eyes of consumers and therefore increases a firm's pricing power. Pricing power was measured by retailer's average premium or discount relative to competitors. In the case of premium, better pricing power means that a retailer can charge a higher price premium than that offered by competitors. The impact of review rating on price has been widely documented in the online auction examples. Melnik and Alm (2002) showed that seller's reputation had a positive but small impact on the price using eBay's auction example. As a result those highly rated firms have increased pricing power compared to those with lower ratings. The hotel industry uses revenue per available room (RevPAR) to measure the overall financial performance by taking both price (ADR) and occupancy rate into consideration.

Unlike many tangible products, service offerings like hotel rooms are capacity constrained. Hotels can therefore drive RevPAR by keeping price low and maximizing occupancy or pricing at a premium and increasing margins. We argue that different types of hotels have varying ability to take advantage of the pricing power afforded by social media ratings. Luxury properties are 
constrained in their ability to lower price to drive occupancy given the strong association between price and prestige in the luxury market. Though luxury properties with excess capacity might benefit from higher RevPAR in the short run by lowering the price of unsold rooms, lowering price might negatively impact brand equity. Midscale properties are also constrained in their ability to lower price given their tight margins. Midscale properties are also limited in their ability to raise price given that competition with higher class properties requires a greater selection of amenities. Properties classified between midscale and luxury have greater flexibility related to price as they have freedom to compete with those properties that are above or below them in related hotel class. We argue that when controlling for occupancy, the impact of online WOM on ADR will be represented by an inverted U-shape relationship, with a greater impact of WOM on categories with more pricing depth (i.e., products positioned within categories of diverse offerings). We therefore propose the following:

H3: When controlling for occupancy, online consumer review ratings, will have greater influence on a firm's pricing power (ADR) for product categories with more depth.

\section{DATA, METHOD AND RESULTS}

In the following section we outline tests of our hypotheses. We use two data sources in testing the hypotheses at the aggregate level. We then use one additional data source examining choice data at the individual level as a robustness check.

\section{WOM and Firm Performance}


We analyze the effect of social presence on overall hotel performance using combined performance data and online reputation data. Performance data are derived from quarterly revenue, demand, and supply data from Smith Travel Research (STR) for 2- 1/2 years (January 2010 through June 2012). We have these data for 10 major markets (5 European and 5 North American cities).

We use ReviewPro's Global Review Index (GRI) as a measure of online reputation. ReviewPro aggregates hundreds of millions of social media mentions, in over 35 languages, from Online Travel Agencies, review websites and social media platforms. Their GRI is an aggregate online reputation score for an individual hotel. It is based on scores given by reviewers on major online review sites and online travel agencies. The GRI is calculated by analyzing quantitative scores on these sites, using a proprietary algorithm. ${ }^{1} \quad$ Table 1 summarizes means and standard deviations for our RevPAR measure as well as our WOM measure across hotel type as defined by $\mathrm{STR}^{2}$.

In order to account for heterogeneity in different product classes we calculate the variance in GRI score for each type of hotel property. We show that variance in GRI, as measured by both the standard deviation and the coefficient of variation (standard deviation/average), decreases monotonically with increasing hotel class level thus providing a natural measure of heterogeneity. We use this natural heterogeneity in hotel type to test $\mathrm{H} 2$ related to our hypothesized moderation of between GRI score and firm performance.

-Insert Table 1 Here-

We have this performance and WOM data at the firm and competitive set level, where the competitive set is a list of hotels (typically 5-10) specified by the firm as its major competitors. With

\footnotetext{
1 More details on the Global Review Index can be found at http://www.reviewpro.com/product/global-review-index.

2 Actual hotel names are disguised so we are unable to classify hotels in the same manner as in the choice data set.
} 
this combined data set we look at the impact of WOM on firm performance. Given the potential seasonal nature of hotel demand (and resulting prices) we use relative measures versus absolute measures for our variables; specifically we create RevPAR and GRI Indexes - e.g. a firm's quarterly RevPAR divided by the average quarterly RevPAR of its competitive set. We then look at the impact of these relative performance measures as a function of the GRI index (firms GRI divided by average GRI of its competitive set). Thus the measurements are the effect of GRI (through GRI Index) on a hotel's performance as measured by its RevPAR Index. Similar to many marketing actions (e.g., advertising and pricing) we can anticipate decreasing marginal returns. That is, as the GRI score increases the additional impact upon performance decreases. To incorporate decreasing marginal returns, we use a multiplicative model of impact often referred to as a constant elasticity model.

Price elasticity of demand is defined as the percentage change in demand for a given percentage change in price. So, for example, if price increased by 1 percent and as a result demand fell 2 percent, then elasticity is $-2(-2 \% / 1 \%)$. Using data from over 10,438 quarterly observations from our 10 cities, we look at the impact of GRI upon performance in this log linear framework where we model the impact of $\ln$ (GRI Index) upon $\ln ($ RevPAR Index) as a log linear model. Table 2 summarizes these elasticities for GRI upon RevPAR.

-Insert Table 2 Here-

Table 2 confirms hypothesis 1 (Higher online consumer review ratings are positively related to a firm's financial performance (RevPAR)) with a one percent increase in a firm's GRI resulting in a $0.99045 \%$ increase in RevPAR significant at the 0.0001 level.

Hypothesis 2 indicated that these impacts would be moderated by heterogeneity (The impact of online consumer review ratings on a firm's financial performance (RevPAR) will be moderated a 
product heterogeneity. Online consumer review ratings will have a greater impact on product classes with greater variance.) To measure the impact of heterogeneity we model the interaction between hotel type and GRI by creating variables that are the product of the hotel type indicators and the GRI Index. As Table 2 indicates there is significant interaction between hotel type and RevPAR with all hotel type effects significant at the 0.0001 level.

To look at the net effect of GRI upon hotel performance for hotel type Luxury through Upper Midscale we add the hotel type interaction impact to the base case GRI impact for Midscale hotels, these are summarized in Table 3 (i.e. 0.49721 for Luxury RevPAR results from 1.45385-0.81316). Table 3 indicates that RevPAR impacts of WOM decrease as properties move up the hotel class level (from Midscale to Luxury) to less heterogeneous product categories as measured by the coefficient of variations in online reviews (GRI) as summarized in Table 1.

-Insert Table 3 Here-

Hypothesis $1 \& 2$ focus on hotel performance as measured by RevPAR whereas the focus of H3 is on how firms capitalize upon WOM in capacity constrained settings (When controlling for occupancy, online consumer review ratings, will have greater influence on firms pricing power (ADR) for product categories with more depth). When looking at WOM impacts on pricing power (as measured by ADR) we need to control for demand (as measured by occupancy) as hotels, like many services, actively manage price in response to demand given the constrained supply of a perishable inventory. Unlike a manufacturer, a service provider cannot simply expand (contract) supply in the face of strong (poor) WOM. As such we expect to see different impacts of WOM upon ADR owing to the position of the firm within the product line. We have argued that firms at the top and lower end of the product spectrum have fewer opportunities to change price whereas firms in the middle of 
the product line have more pricing flexibility - price into higher lines with strong WOM and towards lower products under weak WOM. Table 4 shows parameter estimates from log-linear models testing $\mathrm{H} 3$, where similar to $\mathrm{H} 1$ and $\mathrm{H} 2$ we have both fixed and interaction effects with Table 5 showing the net effect of WOM on ADR. As Table 5 indicates we do observe an inverted U shape for WOM impacts upon ADR with Luxury and Midscale hotels have reduced, but still positive impacts of WOM on ADR, whereas Upscale hotels have the strongest net impact as they have more flexibility or depth in pricing into other product lines.

-Insert Tables 4 and 5 Here-

\section{Online Reviews and Consumer Choice}

Tests of hypotheses $1 \& 2$, as confirmed in Tables $2 \& 3$, are performed using aggregate performance and WOM data and may not be entirely representative of the role of WOM upon firm choice. To provide a robustness check for our findings related to $\mathrm{H} 1$ and $\mathrm{H} 2$ we use a second dataset to explore the effects of review score at the individual rather than aggregate level. If review scores do impact firm performance then we should see similar effects on consumer choice. Our data provided by a major North American Online Travel Agent (OTA) consist of 12,882 hotel reservations made during July 2012 in nine major U.S. cities. For each of these almost 13,000 reservations, we have information as provided by a typical OTA display for the property purchased, as well as all other properties not purchased on the last page the customer looked at prior to selecting the property in question. As a result our sample contains details on 284,733 hotel listings, i.e. the 12,882 hotels booked by consumers and 271,851 hotels that were displayed alongside the booked hotels but which were not booked by consumers. 
In Table 4 we summarize means and standard deviations for key attributes with these descriptives presented for the entire sample as well as separated into booked and not-booked hotels. The attributes we are able to observe include the number of user reviews listed at each hotel (\# Reviews), the average rating (on a 5 point scale) across these reviews (Review Score), the lowest listed price for the hotel (Price, \$), the hotel's position within the list of hotels (Page Rank) with 1 at the top of the page to a max of 200 at the bottom, distance in miles to city center (Distance). As one would expect booked hotels tend to be less expensive than not-booked hotels $(\$ 129.17$ versus \$155.18). Review scores seem to have less of an impact with 3.9 for booked and only slightly lower at 3.89 for not-booked hotels. Booked hotels are also slightly closer to the city center and higher up on the page (lower Page Rank).

-Insert Table 6 Here -

Given the binary nature of booked versus not-booked, we use logistic regression to jointly estimate the impact of the attributes upon property selection. Similar to our earlier tests of $\mathrm{H} 1$ and H2, we use indicator variables for hotel type with continuous variables Page Rank, Distance, Number of Reviews, Review Score and Price. To confirm the moderating role of hotel type heterogeneity we also include interaction effects for hotel type and review scores by creating three variables which are the product of the three hotel type indicators and review scores. We have three hotel type indicators for the four hotel types studied (Midscale, Upper Midscale, Upscale and Upper Upscale) with Midscale our reference scale. We exclude Luxury hotels (4.5 and 5 star hotels) from our analysis as they only represent 431 bookings (out of the almost 13, 000 in our sample). Table 5 summarizes parameter estimates from the logistic regression. 
Interpretation of parameter estimates in logistic regression, especially with the inclusion of interaction effects, is a little less intuitive than ordinary least squares. The odds ratio represents the change in the odds of an option being chosen (that is, odds of the hotel being booked, in this case) given a one-unit change in the attribute. The odds are the probability of being selected divided by probability of not being selected $\left(\frac{P}{1-P}\right)$ and are simply $e^{\text {estimate }}$. The Page Rank value of 0.885 $\left(e^{-0.122}\right)$ demonstrates the negative effect of being lower on the search results. If a hotel is listed at spot 2 versus 1 (or 10 versus 9) its odds of being selected decrease to 0.885 of the odds of being selected when in position 1, or an 11.5-percent decrease in its chances for every notch it drops (all else being equal). Table 6 summarizes the odds ratio estimates. The 1.003 for \# Reviews means for each additional review the odds of a hotel being purchased increase by 1.003 or 0.3 percent, indicating not only is WOM important but also the depth of information used to create that WOM is important.

\section{-Insert Table 8 Here -}

The inclusion of interaction effects between hotel type and review scores means we cannot simply interpret odds ratios for hotel types other than Midscale, but instead need to look at changes in purchase probability using the logistic equation (probability $=\frac{e^{B_{0}+B X}}{1+e^{B_{0}+B X}}$ ). We calculate purchase probabilities by hotel type using attributes averages as summarized in Table 7 , and then we also calculate the purchase probability at these same averages but increase the review scores by 1 . Finally we calculate the change in odds given this increase in review score. For Midscale this is simply $1.24\left(e^{0.2152}\right)$, the odds ratios then decrease to 1.13 for Upper Midscale, 1.11 for Upscale and 1.01 for Upper Upscale. Odds ratios greater than 1 indicate that an increase in the attribute by 1 unit results in the corresponding increasing in odds of being purchased and would directly relate to 
an increase in number of purchases or occupancy. Our findings support our earlier tests of $\mathrm{H} 1$ and $\mathrm{H} 2$ as not only do review scores increase purchase likelihood but the impact of these review scores decreases with increasing hotel class. This replication of our aggregate level results at the customer-choice level further justifies the impact of WOM upon firm performance.

-Insert Table 9 Here -

\section{DISCUSSION}

We show that review scores have a significant and substantive positive relationship with financial performance and choice, with both aggregate performance and consumer choice data. The data also reveal that the influence of online review scores on financial performance and choice is moderated by the heterogeneity of product offering, the causal effect being less prominent for hotel classes with less variation. We also find that luxury and midscale properties have less pricing power than other hotel classes resulting in different strategies related to maximizing RevPAR. These results have implications for both theory and practice.

\section{Implications for Theory}

Our findings contribute to a growing body of work on WOM, examining its effects on firm performance (Luo 2009; Trusov, Bucklin, and Pauwels 2009) and the moderating role product attributes have on the relationship (Zhu and Zhang 2010). Most importantly our data allows us to control for product type while using naturally occurring heterogeneity in product class to test our hypotheses. Our results related to pricing power and product class have implications for revenue management. These results have important implications for service research given the intangible 
nature of service product offerings coupled with the prominence and influence of online referral sites.

Future work could examine the ways different firms work to maximize revenue by reacting to and actively managing online reviews. Research is now focusing on the semantic content and style of online reviews and their impact on consumer behavior (Ludwig et al. 2013). Understanding how various characteristics of a review moderate its effect on performance is an interesting avenue for future research. In addition, as review sites often amend company responses or rebuttals to reviews, the effect these comments have on consumer behavior is an important question still unanswered. Given our findings related to the monotonically decreasing effect on performance, as hotel class level increases we would expect managers in lower scale properties to more proactively manage their online review responses.

One way of managing reviews is posting fake reviews that artificially inflate overall scores. Given the power of reviews to influence firm performance, work examining the potential for falsely generated consumer reviews (Luca and Zervas 2013) has significant potential. If review fraud is motivated by economic incentive then properties that have the most to gain from such activity are more likely going to engage in it. In light of our findings related to the moderating role of hotel type on performance, we would expect competitors in the markets with high variance to engage more in review fraud.

Though we use the context of hotels to examine the relationship between online reviews and financial performance, these findings have implications for other service based industries. Most service based businesses have limited capacity and therefore must set prices to maximize utilization and profits. Hotels and airlines are two examples of industries that dynamically change their prices 
to maximize revenue per unit. Though pricing in restaurants is usually static, there is a growing body of research that points to the potential for variable pricing based on demand (Clifford 2012). Research has shown that increases in aggregate review scores can lead to higher reservation rates (Luca 2011); however, with limited capacity these sellers may not be maximizing their total revenue. Further work needs to be done examining not only demand but performance metrics that take into consideration capacity constraints (e.g. Revenue Per Available Seat).

\section{Implications for Practice}

Reviews and review sites continue to drive sales of service products. Implicitly it seems operators understand the importance of such ratings, as evidenced by the increasingly prominent placement of TripAdvisor and other social media awards at their physical locations. Firms are now spending considerable resources managing social media. Our results point to the importance of such expenditures particularly for properties in markets that have high heterogeneity and when alternative signals, including company generated advertising and branding, are viewed by consumers as less diagnostic of product quality. We find that even within a single product category (hotels) variances in product quality in different product classes may drive differential effects of online reviews on financial performance. Firms competing in segments with high variability may be well served to manage their online reviews to improve their overall financial performance. One way of managing such reviews is to design incentive mechanisms to encourage customers to post reviews, especially for properties that may not have strong brand recognition. Coupons to encourage reviews may be one option. Spending resources responding to negative feedback my also pay dividends. 
Firms that manage the sale of perishable products like hotel rooms have two distinct choices to maximize revenue, they can lower price to drive volume or maintain price at the cost of occupancy. We find that the impact of WOM for luxury hotels and midscale properties is less prominent in terms of pricing power than for other product classes. For Luxury and Midscale properties the impact of WOM on RevPAR is driven less by price management and more from occupancy. Given our results related to the moderating role of hotel type and the existing evidence that price is often used as a quality heuristic (Shiv, Carmon, and Ariely 2005), a tactic based on lowering price to drive volume might not be the best strategy for service/product categories with less depth. Firms looking to manage the risk associated with online review sites might be better served building brand equity and thus lowering the perceived risk associated with their service offering. The long term influence of such revenue management strategies on subsequent reviews and firm performance would an interesting topic for future research.

\section{Limitations}

We acknowledge that several factors that we did not measure may contribute to an organization's financial performance. That said, these results are generalizable to the extent that the factors that are not measured are random across the firms in our sample. Given that our aggregate financial performance results and choice data produce the same results and we create indexes that control for performance among competitive sets we feel that data limitations are minimal. One limitation of ReviewPro's aggregate review score is that the data we obtained and combined did not cover economy outlets. Even with the exclusion of economy properties, we feel that the benefits of using the ReviewPro data outweigh its disadvantages. 
Our dataset also suffers from selection bias. STR is a product that hotel companies must purchase and to opt in to. This in conjunction with our pairing of the ReviewPro further reduces the dataset. Given the challenge of obtaining and pairing this type of data we feel the benefits outweigh the works contribution.

We also examine one particular service sector, the hotel industry. Though the hotel business has some characteristics that differ from other service contexts (e.g. variable pricing), we feel that our results are generalizable to other service contexts given that our theoretical support is grounded in the services marketing literature. Other published papers have used singular contexts to examine the relationship between reviews and performance including books (Chevalier and Mayzlin 2006) and movies (Liu 2006; Elberse and Eliashberg 2003). We contribute to this research stream by examining an experience that has significant economic impact and has large influential aggregators of review scores. 
Table 1: Performance metrics by STR hotel type classification.

\begin{tabular}{llccccc}
\hline \multicolumn{5}{c}{ Hotel Type } & & \\
& \multicolumn{2}{c}{ Luxury } & $\begin{array}{l}\text { Upper } \\
\text { Upscale }\end{array}$ & Upscale & $\begin{array}{l}\text { Upper } \\
\text { Midscale }\end{array}$ & Midscale \\
\hline \multirow{2}{*}{ Number of Observations } & 4385 & 6689 & 8294 & 6044 & 1755 \\
RevPAR* & Average & 290.65 & 163.07 & 125.60 & 100.63 & 85.48 \\
& Std. Deviation & 167.76 & 74.81 & 63.41 & 54.60 & 46.47 \\
& Std. Dev./Average & 0.5771 & 0.4587 & 0.5049 & 0.5426 & 0.5436 \\
& & & & & & \\
ADR** & Average & 359.88 & 207.20 & 155.40 & 126.30 & 104.78 \\
& Std. Deviation & 191.72 & 84.874 & 68.47 & 53.341 & 46.56 \\
& Std. Dev./Average & 0.5327 & 0.4096 & 0.4406 & 0.4223 & 0.4443 \\
& & & & & & \\
GRI*** & Average & 0.8672 & 0.8266 & 0.8074 & 0.7808 & 0.7496 \\
& Std. Deviation & 0.0614 & 0.0643 & 0.0674 & 0.0669 & 0.0831 \\
& Std. Dev./Average & 0.0708 & 0.0778 & 0.0835 & 0.0857 & 0.1109 \\
\hline
\end{tabular}

* Revenue Per Available Room

** Average Daily Rate

*** Global Review Index 
Table 2: Results of elasticities for GRI upon RevPAR,

\begin{tabular}{|c|c|c|}
\hline & Model 1 & Model 2 \\
\hline Parameter & RevPAR & RevPAR \\
\hline \multirow[t]{2}{*}{ Intercept } & $-0.03427 *$ & $-0.11696^{*}$ \\
\hline & $(0.00195)$ & $(0.00893)$ \\
\hline \multirow[t]{2}{*}{ GRI } & $0.99045^{*}$ & $1.45385^{*}$ \\
\hline & $(0.03061)$ & $(0.10241)$ \\
\hline \multirow[t]{2}{*}{ Luxury } & & $0.13028^{*}$ \\
\hline & & $(0.00996)$ \\
\hline \multirow[t]{2}{*}{ Upper Upscale } & & $0.10322 *$ \\
\hline & & $(0.00965)$ \\
\hline \multirow[t]{2}{*}{ Upscale } & & $0.07154 *$ \\
\hline & & $(0.00956)$ \\
\hline \multirow[t]{2}{*}{ Upper Midscale } & & $0.04897 *$ \\
\hline & & $(0.01017)$ \\
\hline \multirow[t]{2}{*}{ Luxury X GRI } & & $-0.95664 *$ \\
\hline & & $(0.12364)$ \\
\hline \multirow[t]{2}{*}{ Upper Upscale X GRI } & & $-0.64069 *$ \\
\hline & & $(0.12798)$ \\
\hline \multirow[t]{2}{*}{ Upscale X GRI } & & $-0.62004 *$ \\
\hline & & $(0.12043)$ \\
\hline \multirow[t]{4}{*}{ Upper Midscale X GRI } & & $-0.35051 * *$ \\
\hline & & $(0.11511)$ \\
\hline & F Value & F Value \\
\hline & $1047.3 *$ & $166.21 *$ \\
\hline
\end{tabular}


Table 3: RevPAR WOM Net effects: Fixed plus Interactions

\begin{tabular}{ll}
\hline Hotel Type & RevPAR \\
\hline Luxury & 0.49721 \\
Upper Upscale & 0.81316 \\
Upscale & 0.83381 \\
Upper Midscale & 1.10334 \\
Midscale & 1.45385 \\
\hline
\end{tabular}


Table 4: Results of elasticities for GRI upon ADR,

\begin{tabular}{|c|c|}
\hline Parameter & ADR \\
\hline \multirow[t]{2}{*}{ Intercept } & $-0.05358 *$ \\
\hline & $(0.00255)$ \\
\hline \multirow[t]{2}{*}{ Occupancy } & $-0.13598 *$ \\
\hline & $(0.00857)$ \\
\hline \multirow[t]{2}{*}{ GRI } & $0.92142 *$ \\
\hline & $(0.03392)$ \\
\hline \multirow[t]{2}{*}{ Luxury } & $0.14022 *$ \\
\hline & $(0.00456)$ \\
\hline \multirow[t]{2}{*}{ Upper Upscale } & $0.05925^{*}$ \\
\hline & $(0.00371)$ \\
\hline \multirow[t]{2}{*}{ Upscale } & $0.02874^{*}$ \\
\hline & $(0.00359)$ \\
\hline \multirow[t]{2}{*}{ Upper Midscale } & $0.02235^{*}$ \\
\hline & $(0.00429)$ \\
\hline \multirow[t]{2}{*}{ Luxury X GRI } & $-0.25667 *$ \\
\hline & $(0.05814)$ \\
\hline \multirow[t]{2}{*}{ Upper Upscale X GRI } & -0.11078 \\
\hline & $(0.07548)$ \\
\hline \multirow[t]{2}{*}{ Upscale X GRI } & $0.11772 * *$ \\
\hline & $(0.05131)$ \\
\hline \multirow[t]{4}{*}{ Upper Midscale X GRI } & 0.0367 \\
\hline & $(0.06782)$ \\
\hline & F Value \\
\hline & 350.13 \\
\hline
\end{tabular}


Table 5: ADR WOM Net effects Fixed plus Interactions

\begin{tabular}{lc}
\hline Hotel Type & RevPAR \\
\hline Luxury & 0.6648 \\
Upper Upscale & $0.8104^{+}$ \\
Upscale & 1.0391 \\
Upper Midscale & $0.9579^{+}$ \\
Midscale & 0.9214 \\
\hline${ }^{+}$Not significantly different from Midscale
\end{tabular}


Table 6: Online reviews and consumer choice descriptive statistics

\begin{tabular}{lllllll}
\hline & & \# Reviews & $\begin{array}{l}\text { Review } \\
\text { Score }\end{array}$ & Price $(\$)$ & $\begin{array}{l}\text { Page } \\
\text { Rank }\end{array}$ & Distance \\
\hline ALL & Average & 34.82 & 3.89 & 154.02 & 15.38 & 14.18 \\
$(284,773)$ & Std. Deviation & 49.52 & 0.74 & 117.09 & 21.96 & 12.59 \\
\cline { 2 - 7 } Booked & Average & 47.54 & 3.90 & 129.17 & 7.04 & 13.82 \\
$(12,882)$ & Std. Deviation & 61.82 & 0.65 & 73.10 & 8.76 & 13.07 \\
\cline { 2 - 7 } Not-Booked & Average & 34.23 & 3.89 & 155.18 & 15.77 & 14.20 \\
$(271,851)$ & Std. Deviation & 48.80 & 0.74 & 118.60 & 22.30 & 12.57 \\
\hline
\end{tabular}

Number of observations in () 
Table 7: Logistic regression parameter estimates

\begin{tabular}{lllll}
\hline Parameter & Estimate & $\begin{array}{l}\text { Standard } \\
\text { Error }\end{array}$ & $\begin{array}{l}\text { Wald } \\
\text { Chi-Square }\end{array}$ & Pr $>$ ChiSq \\
\hline Intercept & -2.1932 & 0.00775 & 800.7347 & $<.0001$ \\
Distance & -0.00294 & 0.000742 & 15.7011 & $<.0001$ \\
Page Rank & -0.122 & 0.0016 & 5832.46 & $<.0001$ \\
\# Reviews & 0.00299 & 0.00015 & 374.292 & $<.0001$ \\
Price & -0.00622 & 0.000171 & 1317.833 & $<.0001$ \\
Review Score & 0.2152 & 0.022 & 95.4831 & $<.0001$ \\
Upper Midscale & 0.6275 & 0.1275 & 24.208 & $<.0001$ \\
Upscale & 0.8588 & 0.2123 & 16.3699 & $<.0001$ \\
Upper Upscale & 1.3849 & 0.2427 & 32.5543 & $<.0001$ \\
Upper Midscale X Review Score & -0.0896 & 0.0336 & 7.1331 & 0.0076 \\
Upscale X Review Score & -0.1232 & 0.0534 & 5.315 & 0.0211 \\
Upper Upscale X Review Score & -0.207 & 0.0592 & 12.2326 & 0.0005 \\
\hline
\end{tabular}


Table 8: Logistic regression odds ratio estimates

\begin{tabular}{ll}
\hline \multicolumn{1}{c}{ Parameter } & Point Estimate \\
\hline Distance & 0.997 \\
Page Rank & 0.885 \\
\# Reviews & 1.003 \\
Price & 0.994 \\
\hline
\end{tabular}


Table 9: Net review score impact

\begin{tabular}{lcccccc}
\hline & Rank & Price & \# Reviews & Distance & $\begin{array}{c}\text { Review } \\
\text { Score }\end{array}$ & $\begin{array}{c}\text { Relative } \\
\text { Probability }\end{array}$ \\
\hline Midscale & 16.7 & 89.4 & 21.3 & 15.4 & 3.4 & 1.24 \\
Upper Midscale & 17 & 131 & 29.9 & 15.1 & 4 & 1.13 \\
Upscale & 14.7 & 159.8 & 46.6 & 13 & 4.1 & 1.09 \\
Upper Upscale & 12.3 & 218.9 & 53.2 & 12.1 & 4.2 & 1.01 \\
\hline
\end{tabular}




\section{References}

Anderson, Michael, and Jeremy Magruder. 2012. "Learning from the Crowd: Regression Discontinuity Estimates of the Effects of an Online Review Database* Learning from the Crowd: Regression Discontinuity Estimates of the Effects of an Online Review Database." Economic Journal 122 (563): 957-89.

Archak, Nikolay, Anindya Ghose, and Panagiotis G. Ipeirotis. 2011. "Deriving the Pricing Power of Product Features by Mining Consumer Reviews.” Management Science 57 (8): 1485-1509. doi:10.1287/mnsc.1110.1370.

Berger, Jonah, Alan T Sorensen, and Scott J Rasmussen. 2010. "Positive Effects of Negative Publicity: When Negative Reviews Increase Sales.” Marketing Science 29 (5): 815-27.

Bickart, Barbara, and Robert M. Schindler. 2001. "Internet Forums as Influential Sources of Consumer Information.” Journal of Interactive Marketing 15 (3): 31-40.

Blank, Grant. 2007. Critics, Ratings, and Society: The Sociology of Reviews. Rowman \& Littlefield.

Chevalier, Judith A., and Dina Mayzlin. 2006. "The Effect of Word of Mouth on Sales: Online Book Reviews." Journal of Marketing Research (JMR) 43 (3): 345-54.

Clifford, Stephanie. 2012. "When It Comes to Reservations, Time Is Money." The New York Times, September 5, sec. D.

Dellarocas, Chrysanthos. 2003. "The Digitization of Word of Mouth: Promise and Challenges of Online Feedback Mechanisms.” Management Science 49 (10): 1407-24.

- 2006. "Strategic Manipulation of Internet Opinion Forums: Implications for Consumers and Firms." Management Science 52 (10): 1577-93.

Eberl, Markus, and Manfred Schwaiger. 2005. "Corporate Reputation: Disentangling the Effects on Financial Performance." European Journal of Marketing 39 (7/8): 838-54. doi:10.1108/03090560510601798.

Elberse, Anita, and Jehoshua Eliashberg. 2003. "Demand and Supply Dynamics for Sequentially Released Products in International Markets: The Case of Motion Pictures." Marketing Science 22 (3): 329-54.

Eliashberg, Jehoshua, and Steven M. Shugan. 1997. "Film Critics: Influencers or Predictors?" Journal of Marketing 61 (2): 68. doi:10.2307/1251831.

Ellison, G., and D. Fudenberg. 1995. "Word-of-Mouth Communication and Social Learning." The Quarterly Journal of Economics 110 (1): 93-125.

Erdem, Tülin, Joffre Swait, and Jordan Louviere. 2002. "The Impact of Brand Credibility on Consumer Price Sensitivity.” International Journal of Research in Marketing 19 (1): 1-19. 
Forman, Chris, Anindya Ghose, and Batia Wiesenfeld. 2008. "Examining the Relationship Between Reviews and Sales: The Role of Reviewer Identity Disclosure in Electronic Markets." Information Systems Research 19 (3): 291-313.

Godes, David, and Dina Mayzlin. 2004. "Using Online Conversations to Study Word-of-Mouth Communication.” Marketing Science 23 (4): 545-60.

Gotsi, Manto, and Alan M. Wilson. 2001. "Corporate Reputation: Seeking a Definition.” Corporate Communications: An International Journal 6 (1): 24-30. doi:10.1108/13563280110381189.

Herbig, Paul, and John Milewicz. 1993. "The Relationship of Reputation and Credibility to Brand Success.” Journal of Consumer Marketing 10 (3): 18-24.

Libai, Barak, Ruth Bolton, Marnix S. Bügel, Ko de Ruyter, Oliver Götz, Hans Risselada, and Andrew T. Stephen. 2010. "Customer-to-Customer Interactions: Broadening the Scope of Word of Mouth Research.” Journal of Service Research 13 (3): 267-82.

Liu, Yong. 2006. "Word of Mouth for Movies: Its Dynamics and Impact on Box Office Revenue." Journal of Marketing 70 (3): 74-89.

Luca, Michael. 2011. "Reviews, Reputation, and Revenue: The Case of Yelp.com.” Working Papers -- Harvard Business School Division of Research, September, 2-39.

Luca, Michael, and Georgios Zervas. 2013. "Fake It Till You Make It: Reputation, Competition, and Yelp Review Fraud.” Harvard Business School NOM Unit Working Paper, no. 14-006.

Lucking-Reiley, David, Doug Bryan, Naghi Prasad, and Daniel Reeves. 2007. "Pennies from Ebay: The Determinants of Price in Online Auctions*." The Journal of Industrial Economics 55 (2): 223-33.

Ludwig, Stephan, Ko de Ruyter, Mike Friedman, Elisabeth C Brüggen, Martin Wetzels, and Gerard Pfann. 2013. "More Than Words: The Influence of Affective Content and Linguistic Style Matches in Online Reviews on Conversion Rates." Journal of Marketing 77 (1): 87-103. doi:10.1509/jm.11.0560.

Luo, Xueming. 2009. "Quantifying the Long-Term Impact of Negative Word of Mouth on Cash Flows and StockPrices." Marketing Science 28 (1): 148-65.

Lutz, Richard J., and Patrick J. Reilly. 1974. "An Exploration of the Effects of Perceived Social and Performance Risk on Consumer Information Acquisition." Advances in Consumer Research 1 (1): 393-405.

Murray, Keith B. 1991. "A Test of Services Marketing Theory: Consumer Information Acquisition Activities.” Journal of Marketing 55 (1): 10. 
Murray, Keith B., and John L. Schlacter. 1990. "The Impact of Services versus Goods on Consumers' Assessment of Perceived Risk and Variability." Journal of the Academy of Marketing Science 18 (1): $51-65$.

Reinstein, David A., and Christopher M. Snyder. 2005. "The Influence of Expert Reviews on Consumer Demand for Experience Goods: A Case Study of Movie Critics." Journal of Industrial Economics 53 (1): 27-51.

Resnick, Paul, R. Zeckhauser, J. Swanson, and K. Lockwood. 2006. "The Value of Reputation on eBay: A Controlled Experiment.” Experimental Economics 9 (2): 79-101.

Resnick, Paul, and Richard Zeckhauser. 2002. "Trust among Strangers in Internet Transactions: Empirical Analysis of eBay' S Reputation System." Advances in Applied Microeconomics 11 (October): 127-57. doi:10.1016/S0278-0984(02)11030-3.

Rindova, Violina P., Ian O. Williamson, Antoaneta P. Petkova, and Joy Marie Sever. 2005. "Being Good or Being Known: An Empirical Examination of the Dimensions, Antecedents, and Consequences of Organizational Reputation." Academy of Management Journal 48 (6): 1033-49. doi:10.5465/AMJ.2005.19573108.

Ross, Ivan. 1975. "Perceived Risk and Consumer Behavior: A Critical Review." Advances in Consumer Research 2 (1): 1.

Senecal, Sylvain, and Jacques Nantel. 2004. "The Influence of Online Product Recommendation on Consumers' Online Choices.” Journal of Retailing 80 (2): 159-69.

Shapiro, Carl. 1982. "Consumer Information, Product Quality, and Seller Reputation." The Bell Journal of Economics, 20-35.

Shiv, Baba, Ziv Carmon, and Dan Ariely. 2005. "Placebo Effects of Marketing Actions: Consumers May Get What They Pay for." Journal of Marketing Research, 383-93.

Tirunillai, Seshadri, and Gerard J Tellis. 2012. "Does Chatter Really Matter? Dynamics of User-Generated Content and Stock Performance.” Marketing Science 31 (2): 198-215.

Trusov, Michael, Randolph E Bucklin, and Koen Pauwels. 2009. "Effects of Word-of-Mouth Versus Traditional Marketing: Findings from an Internet Social Networking Site." Journal of Marketing 73 (5): 90-102.

Vermeulen, Ivar E., and Daphne Seegers. 2009. "Tried and Tested: The Impact of Online Hotel Reviews on Consumer Consideration." Tourism Management 30 (1): 123-27.

Villanueva, Julian, Shijin Yoo, and Dominique M Hanssens. 2008. "The Impact of Marketing-Induced Versus Word-of-Mouth Customer Acquisition on Customer Equity Growth." Journal of Marketing Research (JMR) 45 (1): 48-59. 
Weigelt, Keith, and Colin Camerer. 1988. "Reputation and Corporate Strategy: A Review of Recent Theory and Applications." Strategic Management Journal 9 (5): 443-54.

Wright, Alice A., and Richard J. Lutz. 1993. "The Framing of Brand Judgments After Direct Product Experience and Advertising: An Empirical...." In AMA Winter Educators' Conference Proceedings, $4: 172$.

Ye, Qiang, Rob Law, and Bin Gu. 2009. "The Impact of Online User Reviews on Hotel Room Sales." International Journal of Hospitality Management 28 (1): 180-82.

Zeithaml, Valarie A. 2000. "Service Quality, Profitability, and the Economic Worth of Customers: What We Know and What We Need to Learn." Journal of the Academy of Marketing Science 28 (1): $67-85$.

Zeithaml, Valarie A., and Mary Jo Bitner. 2003. Services Marketing: Integrating Customer Focus Across the Firm. McGraw-Hill/Irwin.

Zhu, Feng, and Xiaoquan (Michael) Zhang. 2010. "Impact of Online Consumer Reviews on Sales: The Moderating Role of Product and Consumer Characteristics." Journal of Marketing 74 (2): $133-48$. 